\title{
STALLOGRAPHIC ANALYSIS OF FUROSEMIDE: IDENTIFICATION AND QUANTIFICATION OF CRYSTALLINE FRACTION ON ACTIVE INGREDIENT
}

Tita, D. L.*; Antonio, S. G.; Paiva-Santos, C. O.

Department of Physical Chemistry, UNESP, Institute of Chemistry, Araraquara, São Paulo, Brasil

*diego.tita@gmail.com

Furosemide is a diuretic with fast onset and short duration that is used for edema and chronic renal insufficiency. According crystallographic studies there are three polymorphs forms (forms I, II, III). The most thermodynamically stable of the know polymorphs is Form I in the space group $P 1$ with lattice parameters $a=10,467(12) \AA, b=15,801(15)$ $\AA, c=9,584(10) \AA, \alpha=71,87^{\circ}, \beta=115,04^{\circ}$ and $\square=108,48^{\circ}$. X-ray powder diffraction and the Rietveld method are powerful tools for polymorphic identification in commercial tablets. This work reports the study of the polymorphic forms of furosemide and, through the addition of a internal standard, the quantification of the absolute content of crystalline active ingredient (AI) in one Similar tablet of $40 \mathrm{mg}$. X-ray powder diffraction data were obtained in a Rigaku RINT2000 copper $(\mathrm{CuK} \alpha)$ rotation anode diffractometer with a D/teX Ultra 2 linear detector. NIST SRM 676 a (corundum) was used as the internal standard in mixtures of $x \mathrm{wt} \%$ of SRM and $(1-x) \mathrm{wt} \%$ of triturated tablet. The results shown that only the form I is present in the tablet as a AI. In a tablet of about 100 mg formulated with $40 \mathrm{mg}$ of AI, there are $35,92 \mathrm{mg}$ of furosemide crystalline. Theses results are in agreement with Brazilian Pharmacopeia and in the specifications of the package insert. It means that almost $5 \mathrm{wt} \%$ is in amorphous form. The Rietveld method is an adequate tool for the analysis of medicaments. 